\title{
Second generation 4,5,6,7-tetrahydrobenzo[d]thiazoles as novel DNA gyrase inhibitors
}

\section{pÿLamut, Andra}

2020-02

pÿLamut , A , Skok , \}, Baranoková , M , Gutierrez , L J , Cruz , C , Tammela , P , Draskovits pÿ, G, Szili , P É , Nyerges , Á, Pál , C , Molek, P, Bratkovi , T , llaa , J , Zidar , N, Zega , A pÿ, Enriz , R D , Kikelj , D \& Tomaai , T 2020 , ' Second generation 4,5,6,7-tetrahydrobenzo[ d ]thiazoles as novel DNA gyrase inhibitors ' , Future Medicinal Chemistry , vol. 12 , no. 4 , pp. 277-297 . https://doi.org/10.4155/fmc-2019-0127

http://hdl.handle.net/10138/326327

https://doi.org/10.4155/fmc-2019-0127

acceptedVersion

Downloaded from Helda, University of Helsinki institutional repository.

This is an electronic reprint of the original article.

This reprint may differ from the original in pagination and typographic detail.

Please cite the original version. 


\title{
Second Generation 4,5,6,7-Tetrahydrobenzo[ $d]$ thiazoles as Novel
}

\author{
DNA Gyrase Inhibitors
}

\section{Running title: Novel bacterial DNA gyrase B inhibitors}

\begin{abstract}
Aim: DNA gyrase and topoisomerase IV are essential bacterial enzymes, and in the fight against bacterial resistance, they are important targets for the development of novel antibacterial drugs. Results: Building from our first generation of 4,5,6,7-tetrahydrobenzo[ $d]$ thiazole-based DNA gyrase inhibitors, we designed and prepared an optimized series of analogs that show improved inhibition of DNA gyrase and topoisomerase IV from Staphylococcus aureus and Escherichia coli, with $\mathrm{IC}_{50}$ values in the nanomolar range. Importantly, these inhibitors also show improved antibacterial activity against Gram-positive strains. Conclusions: The most promising inhibitor, 29, is active against Enterococcus faecalis, Enterococcus faecium and $S$. aureus wild-type and resistant strains, with MICs between $4 \mu \mathrm{g} / \mathrm{mL}$ and $8 \mu \mathrm{g} / \mathrm{mL}$, which represents good starting point for development of novel antibacterials.
\end{abstract}

SAR investigation:

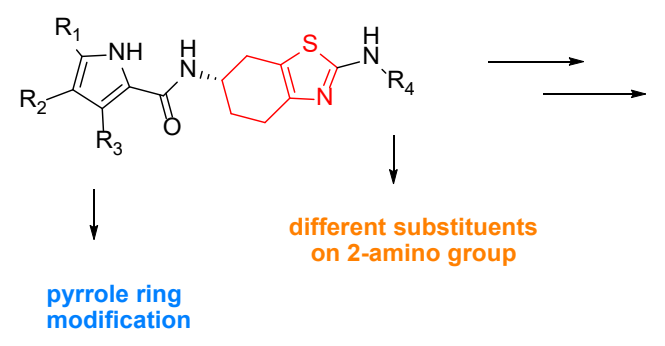

Inhibition of growth of Staphylococcus aureus

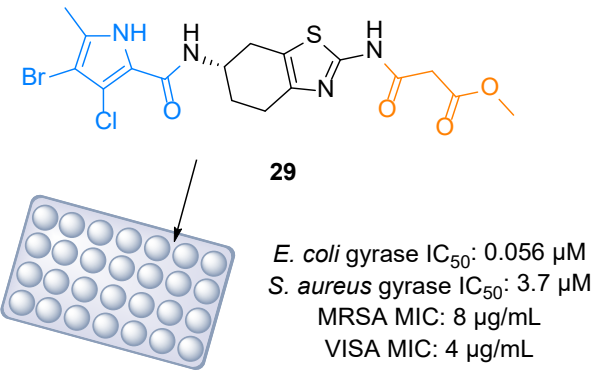

KEYWORDS: antibacterial; DNA gyrase; inhibitor; pyrrolamide; QTAIM; thiazole 


\section{INTRODUCTION}

Many clinically important pathogenic microorganisms have become resistant to the currently available antibiotics. In 2017, the World Health Organization published a list of priority pathogens for which new antibiotic treatments are urgently needed $[1,2]$. The reasons for this development of multidrug-resistant microorganisms include inappropriate prescribing and consuming of antibiotics, false dose regimens, and extensive agricultural use of antimicrobials. The available treatment options for infections caused by multidrug-resistant bacteria have also worsened because of a substantial reduction in newly approved antibacterials over the past two decades [3]. Fortunately, clinicians have recognized bacterial resistance as one of the major human health threats, and antibacterial drug discovery that targets the multidrug-resistant strains has recently gained more research interest. To overcome the issue of antibiotic resistance, there is the need for the development of antibacterial agents with new mechanisms of action [4] and with multi-targeting drugs that simultaneously inhibit different bacterial targets, for which the bacterial development of target-based resistance will be slower [5].

Bacterial topoisomerases have important roles in replication of DNA through their catalysis of modifications to its topological state during replication [6, 7]. Topoisomerase inhibition leads to complete loss of cell viability and bacterial cell death $[7,8]$. DNA gyrase and topoisomerase IV are type IIA topoisomerases that show high structural and sequence similarity and are composed of two subunits, GyrA and ParC, respectively, and GyrB and ParE, which contain the ATPase active site [9]. These two enzymes are validated and attractive targets for antibacterial drug discovery $[10,11]$. The catalytic GyrA and ParC subunits are inhibited by the therapeutically-used fluoroquinolone class of antibiotics [12, 13]. Moreover, inhibition of the ATP-binding GyrB and ParE subunits is also a promising strategy for the development of new antibacterial drugs [9, 10, 14]. For example, the aminocoumarin antibiotic novobiocin (1; Figure 1) was previously used in therapy, although it was withdrawn because of resistance 
development and the discovery of safer and more effective antibacterial drugs [10]. Furthermore, novel DNA gyrase and topoisomerase IV inhibitors that belong to different chemical classes with distinct modes of action are now in clinical development (e.g., gepotidacin, 2 [15]; zoliflodacin, 3 [16]; Figure 1) [11]. The structural similarities between DNA gyrase and topoisomerase IV offer the opportunity to design dual-targeting inhibitors for which the bacterial target-based resistance will develop more slowly compared to compounds that inhibit a single target. Besides, there is no cross-resistance between inhibitors that bind to the catalytic (e.g., fluoroquinolones) and ATPase (e.g., novobiocin) subunits of DNA gyrase and topoisomerase IV [17].

As the targeting of the ATP-binding site of bacterial DNA gyrase can be associated with selectivity issues in terms of human ATP-binding enzymes, determination of the selectivity toward structurally similar enzymes is of great importance [18]. Selectivity of GyrB and ParE inhibitors against eukaryotic topoisomerase II can be achieved by exploiting the important differences between the amino-acid residues that comprise the inhibitor binding sites of the human and bacterial topoisomerases. Moreover, although seldom reported, the selectivity profiles against human protein kinases are usually good $[9,18,19]$. The potential drawback of targeting the ATP-binding site of DNA gyrase still remains toxicity, which was an issue associated with many of the newly discovered DNA gyrase inhibitors in the past [10], and lack of increasing the concentration of enzyme-DNA cleavage complexes, which is the mechanism characteristic for fluoroquinolone class of DNA gyrase inhibitors [20].
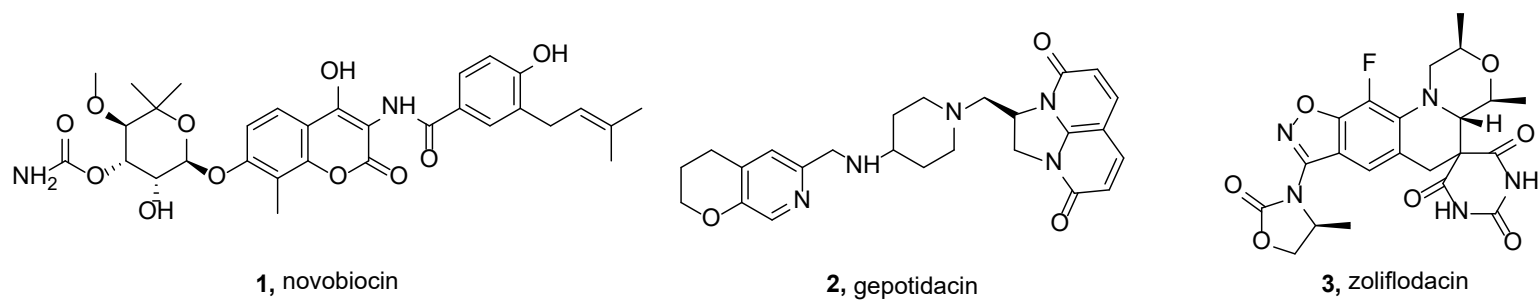

2, gepotidacin

3, zoliflodacin 
Figure 1. DNA gyrase inhibitor novobiocin, and two novel DNA gyrase and topoisomerase IV inhibitors in clinical development.

Our first GyrB inhibitors were discovered through virtual screening of a designed library of marine alkaloid analogs, among which the 4,5,6,7-tetrahydrobenzo[d]thiazoles were shown to be the most potent [21]. Following our initial discovery and optimization of the virtual screening hits [21], we designed and prepared several series of $N$-phenylpyrrolamides as a new structural class of potent GyrB inhibitors with antibacterial activities [22-25]. In addition, the benzothiazole-2,6-diamine scaffold was introduced in the place of the 4,5,6,7tetrahydrobenzo $[d]$ thiazole, to obtain analogs with low nanomolar inhibition of Escherichia coli DNA gyrase and improved inhibition of E. coli topoisomerase IV [26]. To further explore the structure-activity relationships (SARs) of the 4,5,6,7-tetrahydrobenzo[d]thiazoles, a series of »reversed« analogs and ring-opened inhibitors was also synthesized. However, these compounds showed only (sub)micromolar DNA gyrase inhibition and poor antibacterial activities due to the loss of the important cation- $\pi$ interactions in the binding site [27]. A common feature of all of these inhibitors is the pyrrole moiety, which is also found in some other structural classes of GyrB inhibitors with antibacterial properties, such as the natural antibiotics clorobiocin (4; Figure 2) [28] and kibdelomycin [29], as well as synthetic inhibitors like aminothiazoles (5, AZD5099; Figure 2) [30] and N-phenylpyrrolamides (6; Figure 2) [25]. In addition to the pyrrole-containing compounds, potent GyrB and ParE inhibitors were also identified in other structural classes, such as ethyl ureas, which are mainly active against Grampositive bacteria [31] (7; Figure 2), and tricyclic inhibitors [19] (8; Figure 2), which are also active against Gram-negative strains. 

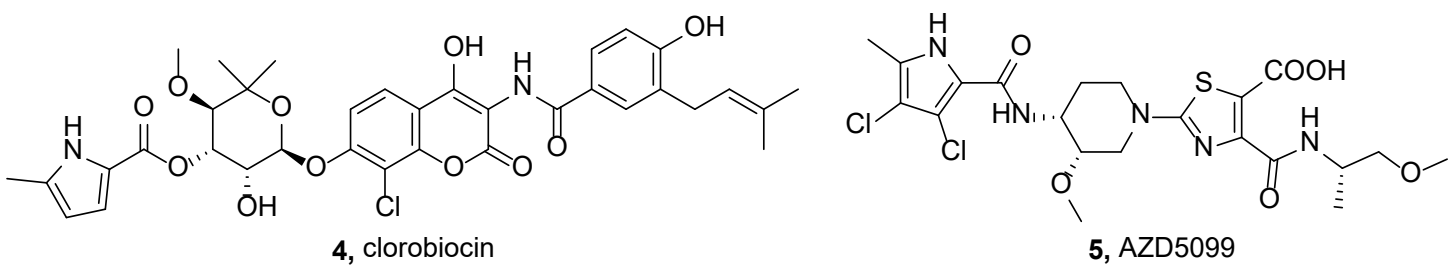

5, AZD5099

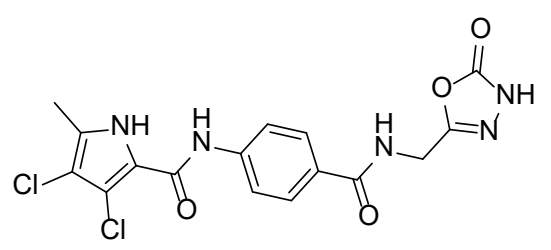

6

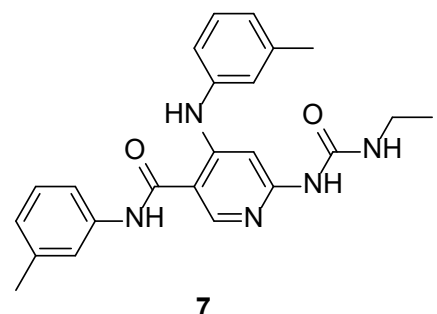

7

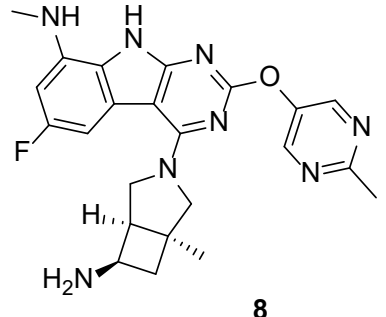

8

Figure 2. Representative GyrB and ParE inhibitors of natural and synthetic origins.

Although the first generation of 4,5,6,7-tetrahydrobenzo[d]thiazole inhibitors showed potent $E$. coli DNA gyrase inhibition, their activities against $E$. coli topoisomerase IV and $S$. aureus DNA gyrase and topoisomerase IV were more than 100 -fold weaker. This thus resulted in poor antibacterial activities against the tested Gram-positive bacterial strains. The compounds were also not active against the tested Gram-negative strains, which was mainly attributed to their poor penetration and active efflux from the bacterial cytoplasm [21]. By measuring the volumes of the hydrophobic pockets of E. coli and S. aureus GyrB and ParE, where the pyrrolamide moiety of inhibitors is bound in the available crystal structures, we noted that the pocket volume in E. coli GyrB is larger compared to the other three enzymes. Therefore, poor inhibition of $S$. aureus DNA gyrase and $S$. aureus and E. coli topoisomerase IV might be explained by steric clashes of the 4,5-dibromo- and 4,5-dichloropyrrolamide moieties in the hydrophobic pocket. The aim of the present study was thus to further explore the SARs around the 4,5,6,7-tetrahydrobenzo[ $d]$ thiazole scaffold, to improve the inhibition of DNA gyrase and topoisomerase IV, which would also result in improved antibacterial activities.

\section{EXPERIMENTAL SECTION}

\subsection{Materials and methods}


The chemicals were obtained from Acros Organics (Geel, Belgium), Sigma-Aldrich (St. Louis, MO, USA), TCI Europe N.V. (Zwijndrecht, Belgium), and Apollo Scientific (Stockport, UK), and were used without further purification. Analytical TLC was performed on silica gel Merck $60 \mathrm{~F}_{254}$ plates $(0.25 \mathrm{~mm})$, using visualization with UV light and spray reagents. Column chromatography was carried out on silica gel 60 (particle size, 240-400 mesh). HPLC analyses were performed on: (i) Agilent Technologies 1100 instrument with a UV-VIS detector (G1365B), a thermostat (G1316A), an autosampler (G1313A) and a C18 column (Eclipse Plus; $5 \mu \mathrm{m}, 4.6 \times 150 \mathrm{~mm}$; Agilent); (ii) Thermo Scientific Dionex Ultimate 3000 Binary Rapid Separation LC System (Thermo Fisher Scientific, Waltham, MA, USA) with an autosampler, a binary pump system, a photodiode array detector, a thermostated column compartment and a C18 column (Zorbax Extend; $3.5 \mu \mathrm{m}, 4.6 \times 150 \mathrm{~mm}$; Agilent). The following gradient elution method was used with mobile phases A ( $0.1 \%$ trifluoroacetic acid in water) and B (acetonitrile): 0-16 $\mathrm{min}, 95 \%-5 \% \mathrm{~A} ; 16-21 \mathrm{~min}, 5 \% \mathrm{~A}$. The flow rate was $1.0 \mathrm{~mL} / \mathrm{min}$, and the injection volume was $20 \mu \mathrm{L}$. All of the tested compounds were $\geq 95 \%$ pure by HPLC. Melting points were determined on a Reichert hot-stage microscope, and are uncorrected. ${ }^{1} \mathrm{H}$ and ${ }^{13} \mathrm{C} \mathrm{NMR}$ spectra were recorded at $400 \mathrm{MHz}$ and $100 \mathrm{MHz}$, respectively, on an AVANCE III 400 spectrometer (Bruker Corporation, Billerica, MA, USA) in DMSO- $d_{6}, \mathrm{CDCl}_{3}$, or $\mathrm{MeOD}-d_{4}$ solutions, with TMS as the internal standard. Mass spectra were obtained using a Q-TOF Premier mass spectrometer (Micromass, Waters, Manchester, UK) or an expression compact mass spectrometer (Advion Inc., Ithaca, USA) or Exactive ${ }^{\mathrm{TM}}$ Plus Orbitrap mass spectrometer (Thermo Fischer Scientific Inc., Waltham, MA 02451 USA). Optical rotations were measured on a polarimeter (241 MC; Perkin-Elmer). The reported values for specific rotation were the means of 10 successive measurements, using an integration time of $5 \mathrm{~s}$. 


\subsection{Determination of inhibitory activities against $E$. coli and $S$. aureus DNA gyrase and topoisomerase IV}

The assays for the determination of $\mathrm{IC}_{50}$ values against $E$. coli and $S$. aureus DNA gyrase and topoisomerase IV were performed according to the previously reported procedures [21].

\subsection{Determination of inhibitory activities against human DNA topoisomerase II}

The inhibitory activities against human DNA topoisomerase II were determined in an assay on streptavidin-coated 96-well microtiter plates (Inspiralis, Thermo Scientific Pierce). First, the plates were rehydrated with buffer $(20 \mathrm{mM}$ Tris-HCl, 0.01\% [w/v] BSA, 0.05\% [v/v] Tween 20, $137 \mathrm{mM} \mathrm{NaCl}, \mathrm{pH}$ 7.6), and then the biotinylated oligonucleotide was immobilized. After washing off the unbound oligonucleotide, the enzyme assay was performed. The reaction volume of $30 \mu \mathrm{L}$ in buffer $(50 \mathrm{mM}$ Tris- $\mathrm{HCl}, 10 \mathrm{mM} \mathrm{MgCl} 2,125 \mathrm{mM} \mathrm{NaCl}, 5 \mathrm{mM}$ dithiothreitol, $0.1 \mu \mathrm{g} / \mathrm{mL}$ albumin, $1 \mathrm{mM}$ ATP, $\mathrm{pH}$ 7.5) contained $1.5 \mathrm{U}$ human DNA topoisomerase II, $0.75 \mu \mathrm{g}$ supercoiled $\mathrm{pNO} 1$ plasmid, and $3 \mu \mathrm{L}$ of the inhibitor solution in $10 \%$ dimethylsulfoxide (DMSO) containing 0.008\% (v/v) Tween 20. The reaction solutions were incubated at $37^{\circ} \mathrm{C}$ for $30 \mathrm{~min}$. Then, TF buffer $(50 \mathrm{mM} \mathrm{NaOAc}, 50 \mathrm{mM} \mathrm{NaCl}, 50 \mathrm{mM} \mathrm{MgCl}$, $\mathrm{pH}$ 5.0) was added to terminate the enzymatic reaction. After an additional incubation for 30 min at room temperature, during which the biotin-oligonucleotide-plasmid triplex was formed, the unbound plasmid was washed off using TF buffer, and Diamond Dye was added in T10 buffer (10 mM Tris-HCl, $1 \mathrm{mM}$ EDTA, $\mathrm{pH}$ 8.0). The fluorescence was measured with a microplate reader (BioTek Synergy H4; excitation, $485 \mathrm{~nm}$; emission, $537 \mathrm{~nm}$ ). The initial screening was at $100 \mu \mathrm{M}$ or $10 \mu \mathrm{M}$ inhibitor. For the most active inhibitors, the $\mathrm{IC}_{50}$ values were determined using seven concentrations of the tested compounds. The GraphPad Prism 6 software was used to calculate the $\mathrm{IC}_{50}$ values. The results are reported as the mean values of three independent measurements. Etoposide was used as the positive control ( $\left.\mathrm{IC}_{50}, 59 \mu \mathrm{M}\right)$. 


\subsection{Determination of antibacterial activities}

Clinical microbiology control strains of E. faecalis (ATCC 29212), S. aureus (ATCC 25923), E. coli (ATCC 25922), P. aeruginosa (ATCC 27853), E. faecium (ATCC 700221), and vancomycin-intermediate $S$. aureus (ATCC 700699) were obtained from Microbiologics Inc. (St. Cloud, MN, USA). Methicillin-resistant S. aureus (ATCC 43300), and S. aureus (ATCC 29213) strains, which were used for additional testing (Table 6), were obtained from the University of Szeged (Hungary). Single-gene knock-out mutant strains of E. coli JW5503 (tolC knock-out) and JD17464 (lpxC knock-out) were obtained from the E. coli collection of the National BioResource Project at the National Institute of Genetics (Japan) [32]. E. coli K-12 MG1655 lines carrying the clinically most commonly observed fluoroquinolone resistance mutations (GyrA S83L, D87N, D87Y; ParC S80I, E84G) and the combinations thereof were constructed in-house with the aid of the genome engineering method pORTMAGE, described in detail in previous papers $[33,34]$. To determine the antibacterial activities, broth microdilution assays were carried out in 96-well plates following the Clinical and Laboratory Standards Institute guidelines. For selected compounds, the MICs were determined by construction of the dose-response curves (from at least two independent experiments, each with three replicates per concentration).

\subsection{Molecular modeling}

\subsubsection{Molecular docking}

The crystal structure of E. coli DNA gyrase B in complex with adenylyl-imidodiphosphate (PDB entry: 1EI1 [35]) was used in the docking experiments, as retrieved from the Protein Data Bank. The docking calculations were carried out using the AutoDock 4.2 software [36]. In all of the calculations, the following parameters were used: the initial population of trial ligands comprised 250 individuals; the maximum number of generations was set to 270,000 ; the maximum number of energy evaluations was $10.0 \times 10^{6}$; and all of the other run parameters 
were maintained at their default settings. The docked conformations that resulted were clustered into families considering the backbone root mean square deviation.

\subsubsection{Refinement of the anchoring and QTAIM analysis}

After the docking calculations, the leading lowest energy structures were optimized at the M062X/631G(d) level using quantum mechanics/ molecular mechanics calculations. The inhibitors and the side chains of the residues that had at least one heavy atom within $4 \AA$ from the ligand molecule (i.e., first shell residues) were incorporated into the high-level QM layer using the M06-2X/631G(d) method. The chosen cut-off value resulted from a compromise between computational cost and efficiency $[37,38]$. The remainder of the system was included in the low-level MM layer using the Assisted Model Building with Energy Refinement (AMBER) force field. The MM parameters that were absent in the standard AMBER force field were included from the generalized AMBER force field [39]. These calculations were carried out using the Gaussian 09 package [40]. Then, the optimized geometry for each inhibitor-GyrB complex was used as the input for the QTAIM analysis [41], which was carried out using the Multiwfn software [42], with the wave functions generated at the M06-2X/6-31G(d) level.

\section{RESULTS AND DISCUSSION}

\subsection{Design}

Novel 4,5,6,7-tetrahydrobenzo[d]thiazoles were designed based on the known crystal structures of inhibitors bound to the 43-kDa N-terminal fragment of E. coli GyrB, as described previously by our research group (PDB codes: 4ZVI, 5L3J) [23, 26]. The binding site of GyrB comprises a well-defined hydrophobic pocket that consists of amino-acid residues Val43, Ala47, Val71, Ile78, Val120, and Val167 (E. coli GyrB numbering), and the carboxylate group of Asp73, which together with a conserved water molecule, forms a network of hydrogen bonds with the pyrrole-2-carboxamide moiety of the ligand that mimics the binding of the adenine ring of ATP 
[21]. Finally, additional salt bridge interactions with the Arg136 guanidine group and cation- $\pi$ interactions between the planar aromatic ring and the Arg76 side chain within the Glu50-Arg76 salt bridge are possible in the binding site (Figure 3).

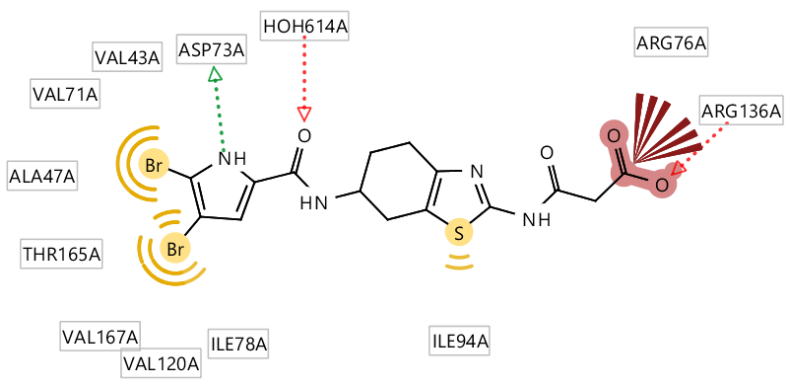

Figure 3. Interactions of representative compound I of the first generation of 4,5,6,7-tetrahydrobenzo[ $d]$ thiazolebased inhibitors in the E. coli GyrB ATP-binding site, as predicted by molecular docking. Hydrophobic interactions are shown in yellow, hydrogen bonds as dashed arrows and negative charge is shown in red.

In the second generation 4,5,6,7-tetrahydrobenzo[d]thiazoles, we retained the pyrrole2-carboxamide moiety to form hydrogen bonds with the binding site residues, as shown in Figure 3, while examining the steric fit of differently substituted pyrroles of varying sizes (Table 1, type I compounds) with the hydrophobic pocket of GyrB and ParE of E. coli and S. aureus. As the acidity of the pyrrole NH group was shown to have an important role in the binding of compounds through an influence on the strength of the hydrogen bond with the Asp73 side chain [21], we incorporated different numbers of chloro and/or bromo substituents with negative inductive effects at positions 3,4 , and 5 of the pyrrole ring. In addition, a methyl group was introduced at position 5 of the pyrrole moiety, to increase the hydrophobic interactions within the enzyme pyrrolamide binding pocket. While modifying the pyrrole moiety, the malonyl substituent on the amino group at position 2 of the 4,5,6,7-tetrahydrobenzo[ $d]$ thiazole core was kept constant (Figure 3) [21].

In the second stage, we fixed the pyrrolamide moiety by using either a 4,5-dibromo- or 3,4-dichloro-5-methylpyrrolamide and introduced different functionalities at position 2 of the 
4,5,6,7-tetrahydrobenzo[ $d]$ thiazole core, which were selected to achieve additional polar interactions (i.e., hydrogen bonds and/or ionic interactions) with the positively charged sidechain guanidine groups of Arg76 and/or Arg136. The 1,3,4-oxadiazol-2-one ring was introduced as a carboxylic acid bioisostere, as it can form similar interactions with Arg136. At the same time, it is less acidic, and therefore we expected it to improve the cell-wall penetration of the compounds, and consequently their antibacterial activities [25]. Aromatic rings in compounds of the type II and III series (Tables 3, 4) were introduced to form cation- $\pi$ interactions and/or hydrogen bonds with Arg136, which would improve enzyme inhibition. In all type I-III compounds, only the $(S)$-enantiomers were prepared, as the $(R)$-enantiomers were previously shown to be weaker inhibitors of DNA gyrase than their $(S)$-antipodes [21].

\subsection{Chemistry}

All of the compounds were synthesized from the parent $(S)-4,5,6,7$-tetrahydrobenzo $[d]$ thiazole2,6-diamine (9; Scheme 1), which represents the central scaffold of the designed inhibitors and was obtained according to the published procedure [43]. All of the substituted pyrroles used for the preparation of type I compounds were also synthesized according to the reported procedures [44]. Pyrrole-2-carboxylic acids were coupled to the 6-amino group of the central scaffold by 1-ethyl-3-(3-(dimethylamino)propyl)-carbodiimide (EDC)/1-hydroxybenzotriazole (HOBt)-promoted amide-bond formation, while the 2-trichloroacetylpyrroles were attached by heating the reaction mixtures in the presence of a base (Scheme 1), to obtain compounds 10-19. In the next step, acylation of the 2-amino group of 10-19 with methyl 3-chloro-3-oxopropanoate or ethyl 2-chloro-2-oxoacetate in the presence of triethylamine gave esters $\mathbf{2 0 - 3 0}$, which were hydrolyzed with $1 \mathrm{M} \mathrm{NaOH}$ to the carboxylic acids 31-41. Esters 20 and 26 were treated with hydrazine hydrate in dry ethanol, to obtain the hydrazides 42 and 43 (Scheme 2). Compound 
43 was then cyclized to the 1,3,4-oxadiazol-2-one derivative $\mathbf{4 4}$ (Scheme 2) in the presence of 1,1'-carbonyldiimidazole (CDI).

Sulfonamides 50 and $\mathbf{5 1}$ were prepared as shown in Scheme 3. The tert-butylcarbamate 45 was first reacted with methanesulfonyl chloride to obtain the sulfonamide 46, which was then deprotected by acidolysis using $\mathrm{HCl}$ generated in situ by addition of acetyl chloride to methanol. The compound obtained, 48, was then reacted with 2,2,2-trichloro-1-(4,5-dibromo1H-pyrrol-2-yl)ethan-1-one or 3,4-dichloro-5-methyl-1H-pyrrole-2-carboxylic acid, to yield compounds 50 and 51, respectively. Additionally, compound 45 was treated with ethyl isocyanate, to obtain the Boc-protected ethylurea 47. This Boc-protected ethylurea was converted to the amine 49 by acidolysis, which after coupling with 2,2,2-trichloro-1-(4,5dibromo-1H-pyrrol-2-yl)ethan-1-one gave the ethylurea 52. Alternatively, its 3,4-dichloro-5methyl-1H-pyrrole-based counterpart, 53, was prepared by reacting amine 15 with ethyl isocyanate (Scheme 4). Compound 54 was prepared by acetylation of $\mathbf{1 5}$, while amides 55-62 and 65-70 were prepared from 10 or 15 by EDC/HOBt or 2-(1H-benzotriazole-1-yl)-1,1,3,3tetramethylaminium tetrafluoroborate (TBTU)-promoted coupling with aromatic carboxylic acids (Scheme 4). Alkaline hydrolysis of 61 and 62 gave 63 and 64, respectively, while acidolysis of 69 yielded the amine 71 (Scheme 4).

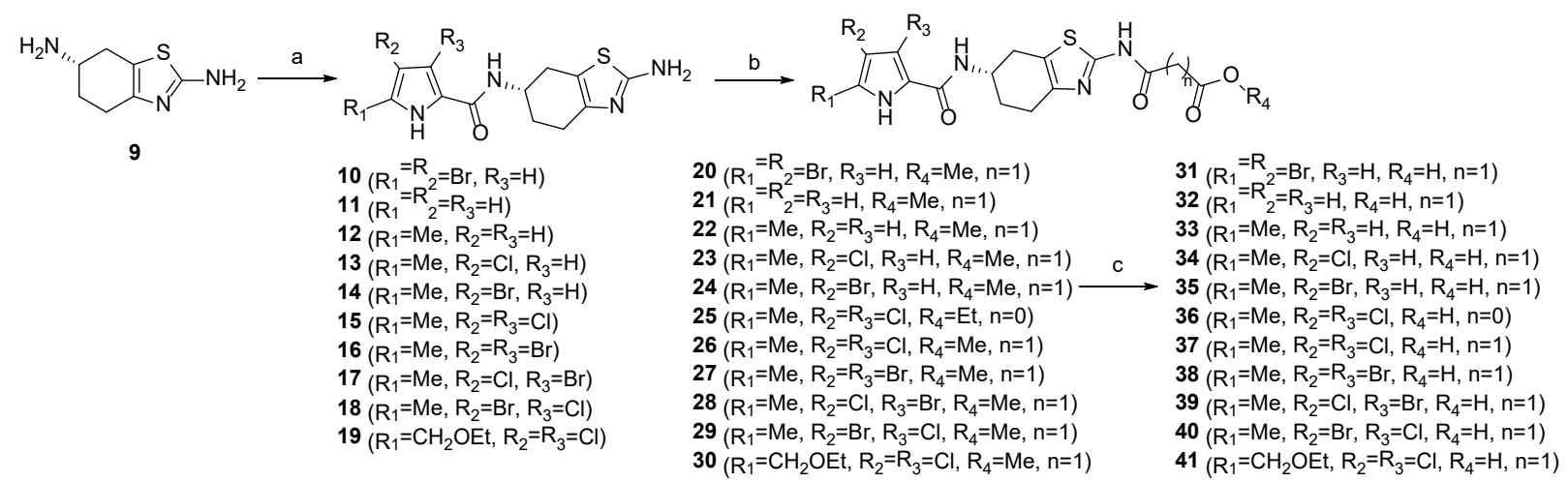

Scheme 1. Reagents and conditions. (a) For 10-14 and 16: corresponding 2,2,2-trichloro-1-(1H-pyrrol-2-yl)ethan1-one, $\mathrm{Na}_{2} \mathrm{CO}_{3}$, DMF, $40{ }^{\circ} \mathrm{C}, 4 \mathrm{~h}$; for 15 and 17-19: corresponding pyrrole-2-carboxylic acid, EDC, HOBt, NMM, 
DMF, r.t., 18 h. (b) For 20-24 and 26-30: methyl 3-chloro-3-oxopropanoate, Et ${ }_{3} \mathrm{~N}, 1$,4-dioxane, r.t., 18 h; for 25 : ethyl 2-chloro-2-oxoacetate, $\mathrm{Et}_{3} \mathrm{~N}, 1$,4-dioxane, r.t., 18 h. (c) $1 \mathrm{M} \mathrm{NaOH}, \mathrm{MeOH}$, r.t., 18 h.

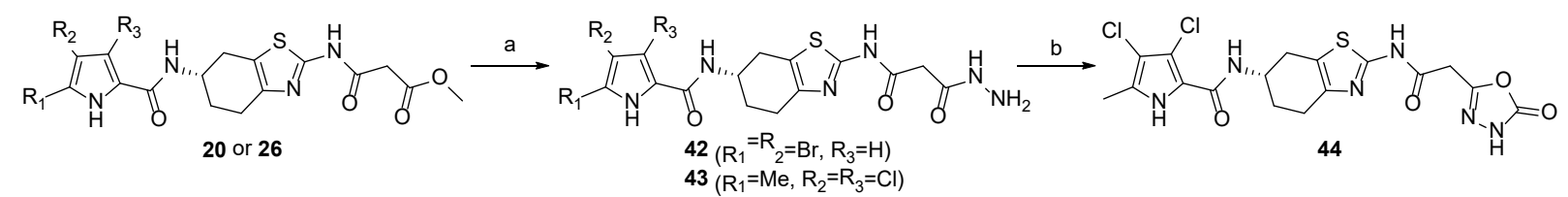

Scheme 2. Reagents and conditions. (a) Hydrazine hydrate, EtOH, $80^{\circ} \mathrm{C}, 18 \mathrm{~h}$. (b) CDI, DMF, $100{ }^{\circ} \mathrm{C}, 18 \mathrm{~h}$.

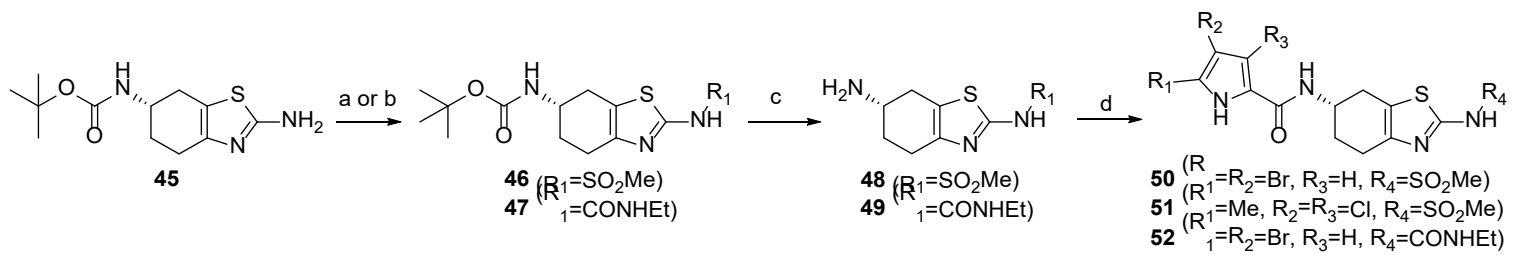

Scheme 3. Reagents and conditions. (a) For 46: methanesulfonyl chloride, pyridine, $0{ }^{\circ} \mathrm{C}, 18$ h. (b) For 47: ethyl isocyanate, $\mathrm{CHCl}_{3}$, r.t., 18 h. (c) Acetyl chloride, $\mathrm{MeOH}, 0^{\circ} \mathrm{C}, 1$ h, then r.t., 18 h. (d) For 50 and 52: 2,2,2-trichloro1-(4,5-dibromo-1H-pyrrol-2-yl)ethan-1-one, $\mathrm{Na}_{2} \mathrm{CO}_{3}$, DMF, $40{ }^{\circ} \mathrm{C}, 4 \mathrm{~h}$; for 51: 3,4-dichloro-5-methyl- $1 H$-pyrrole2-carboxylic acid, EDC, HOBt, NMM, DMF, r.t., 18 h.

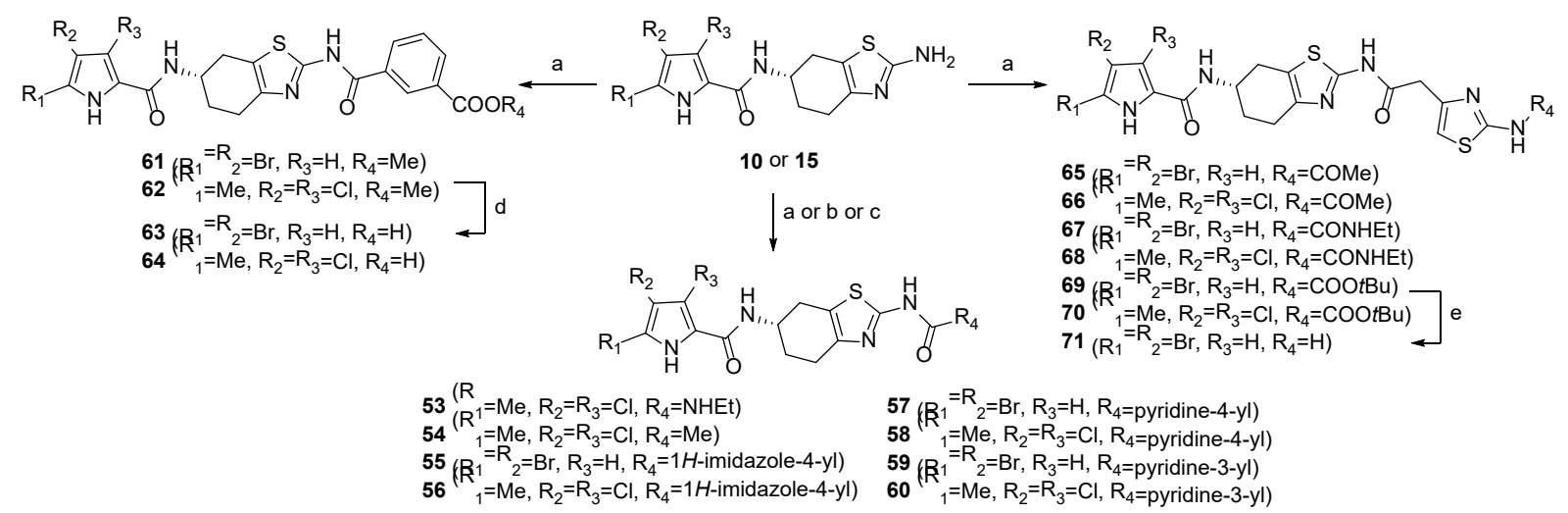

Scheme 4. Reagents and conditions. (a) For 55, 57, 59-62, 65-70: carboxylic acid, EDC, HOBt, NMM, DMF; for 56 and 58: carboxylic acid, TBTU, $\mathrm{Et}_{3} \mathrm{~N}, \mathrm{CH}_{2} \mathrm{Cl}_{2}$, r.t., 24 h. (b) For 53: ethyl isocyanate, $\mathrm{CHCl}_{3}$, r.t., 18 h. (c) For 54: acetyl chloride, $\mathrm{Et}_{3} \mathrm{~N}, 1$,4-dioxane, r.t., 18 h. (d) $1 \mathrm{M} \mathrm{NaOH}, \mathrm{MeOH} / \mathrm{H}_{2} \mathrm{O}$, r.t., 24 h. (e) Acetyl chloride, $\mathrm{MeOH}$, $0{ }^{\circ} \mathrm{C}, 1 \mathrm{~h}$, then r.t., $18 \mathrm{~h}$. 


\section{3. In vitro enzyme inhibition}

All of these final compounds (i.e., 20-44, 50-71) were evaluated for their in vitro inhibitory activities against $E$. coli DNA gyrase using the DNA gyrase supercoiling assay. With the exception of some weakly active compounds, all of these inhibitors were also tested in a DNA supercoiling assay using $S$. aureus DNA gyrase, and in a DNA relaxation assay using topoisomerase IV from E. coli and S. aureus. The results obtained are presented in Tables 1-3 as residual activities of the enzymes at $10 \mu \mathrm{M}$ of the tested compound, or as $\mathrm{IC}_{50}$ values for the more potent compounds.

Table 1. Inhibition of Escherichia coli and Staphylococcus aureus DNA gyrase and topoisomerase IV by the 4,5,6,7-tetrahydrobenzo $[d]$ thiazoles 20-41, which contain differently substituted pyrrole moieties (type I compounds).

\begin{tabular}{|c|c|c|c|c|c|c|c|}
\hline \multirow{3}{*}{ Compound } & \multirow{3}{*}{$\mathbf{R}^{1}$} & \multirow{3}{*}{$\mathbf{R}^{2}$} & \multirow{3}{*}{$\mathbf{n}$} & \multicolumn{2}{|c|}{ DNA gyrase } & \multicolumn{2}{|c|}{ Topoisomerase IV } \\
\hline & & & & \multicolumn{2}{|c|}{$\mathrm{IC}_{50}[\mu \mathrm{M}]$ or RA $[\%]^{a}$} & \multicolumn{2}{|c|}{$\mathrm{IC}_{50}[\mu \mathrm{M}]$ or RA $[\%]^{a}$} \\
\hline & & & & E. coli & S. aureus & E. coli & S. aureus \\
\hline $\mathrm{NB}^{b}$ & - & - & - & $\mathrm{IC}_{50}: 0.17$ & $\mathrm{IC}_{50}: 0.040$ & $\mathrm{IC}_{50}: 11$ & $\mathrm{IC}_{50}: 27$ \\
\hline $20^{d}$ & & $\mathrm{Me}$ & 1 & $\mathrm{IC}_{50}: 0.096 \pm 0.060$ & $\mathrm{IC}_{50}: 110 \pm 10$ & $\mathrm{IC}_{50}: 86 \pm 24$ & RA: 74 \\
\hline 21 & & $\mathrm{Me}$ & 1 & RA: 100 & n.t. ${ }^{c}$ & n.t. & n.t. \\
\hline 22 & & $\mathrm{Me}$ & 1 & RA: 94 & n.t. & n.t. & n.t. \\
\hline 23 & & $\mathrm{Me}$ & 1 & $\mathrm{IC}_{50}: 0.32 \pm 0.02$ & $\mathrm{IC}_{50}: 8.4 \pm 0.7$ & RA: 61 & RA: 95 \\
\hline
\end{tabular}



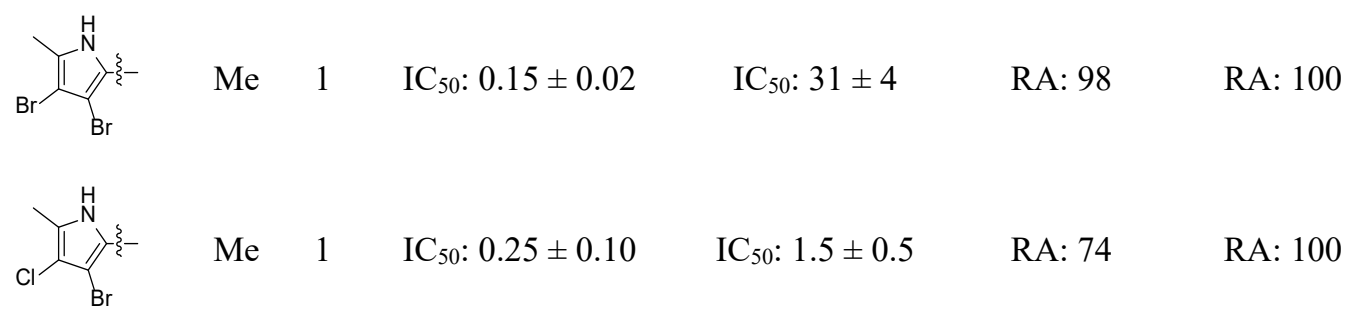

29

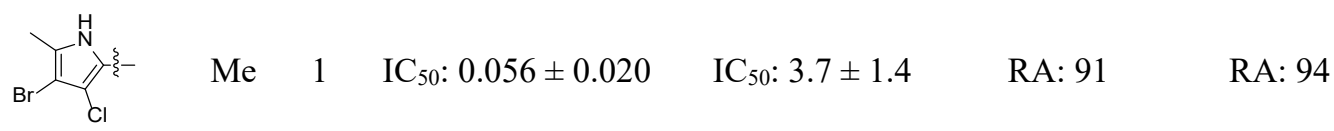

30<smiles></smiles>

RA: 100

n.t.

n.t.

n.t.

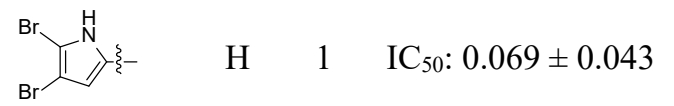

$\mathrm{IC}_{50}: 86 \pm 46$

$\mathrm{IC}_{50}: 74 \pm 30$

$\mathrm{IC}_{50}: 76 \pm 19$

32

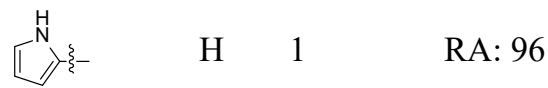

33

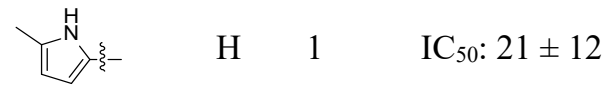

34

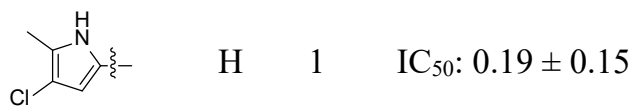

$\mathrm{IC}_{50}: 2.0 \pm 0.2$

RA: 100

RA: 75

35

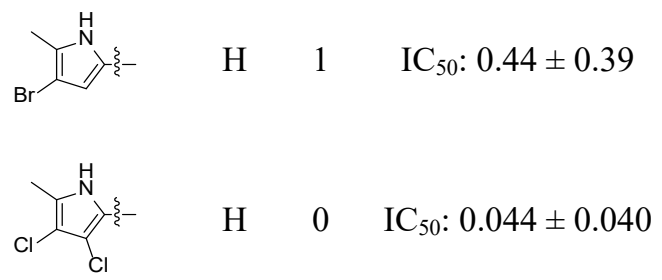

$\mathrm{IC}_{50}: 7.3 \pm 6.2$

$\mathrm{IC}_{50}: 190 \pm$

$\mathrm{IC}_{50}: 8.4 \pm$

36<smiles>Cc1[nH][Y]c(Cl)c1Cl</smiles>

$\mathrm{H} \quad 1 \quad \mathrm{IC}_{50}: 0.022 \pm 0.002$

$\mathrm{IC}_{50}: 0.43 \pm$

50 4.5

37<smiles>Cc1[nH][Y](F)c(Br)c1Br</smiles>

$\mathrm{H} \quad 1 \quad \mathrm{IC}_{50}: 0.020 \pm 0.006$

$\mathrm{IC}_{50}: 12 \pm 6$

RA: 100

RA: 92 
39

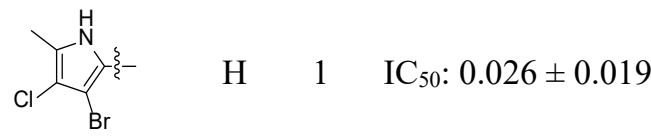

40<smiles>Cc1[nH][Y]c(Cl)c1Br</smiles>

$\mathrm{H}$

$\mathrm{IC}_{50}: 0.016 \pm 0.003$

$\mathrm{IC}_{50}: 1.6 \pm 0.1$

$\mathrm{IC}_{50}: 24 \pm 15$

0.11

RA: 80

$\mathrm{IC}_{50}: 6.6 \pm$

2.8

41<smiles>CCOCc1[nH]cc(Cl)c1Cl</smiles>

H 1 RA: 82

n.t.

RA: 100

RA: 98

${ }^{a} \mathrm{RA}$, residual activity of the enzyme at $10 \mu \mathrm{M}$ tested compound

${ }^{b} \mathrm{NB}$, novobiocin was used as positive control.

${ }^{c}$ n.t., not tested.

${ }^{d}$ data published previously [21]

Type I compounds (Table 1) were designed to explore the differences in the hydrophobic pockets of DNA gyrase and topoisomerase IV from E. coli and S. aureus [21], and to investigate the SARs by varying the hydrophobic character of the pyrrole moiety and the acidity of the pyrrole NH group, which was shown to interact with the Asp73 side chain (Figure 3). In these type I compounds, 13 analogs showed E. coli DNA gyrase inhibition with IC50 values $<0.5 \mu \mathrm{M}$, and with six of these $<0.1 \mu \mathrm{M}$. These six were therefore more potent than the positive control novobiocin $\left(\mathrm{IC}_{50}, 0.17 \mu \mathrm{M}\right)$ as well as our previously published 4,5dibromopyrrole-based compounds $\mathbf{2 0}$ and $\mathbf{3 1}$ [21]. The most potent compound was $\mathbf{4 0}$, with an $\mathrm{IC}_{50}$ of $0.016 \mu \mathrm{M}$ against $E$. coli DNA gyrase, and which displayed good inhibition of all four of these enzymes, with $\mathrm{IC}_{50}$ values of $1.6 \mu \mathrm{M}, 24 \mu \mathrm{M}$, and $0.73 \mu \mathrm{M}$ against $S$. aureus DNA gyrase, and E. coli and S. aureus topoisomerase IV, respectively.

Extensive variations of the substituents on the pyrrole moiety revealed details of the available chemical space inside the hydrophobic pocket of all four of these investigated enzymes. Compounds $\mathbf{2 1}, \mathbf{2 2}, \mathbf{3 2}$, and $\mathbf{3 3}$, containing an unsubstituted pyrrole moiety or only a methyl group on the pyrrole ring, were devoid of inhibitory activity, probably because weak hydrophobic interactions are formed in the hydrophobic pocket. On the other hand, analogs 
with an ethoxymethyl substituent at position 5 of the pyrrole (compounds $\mathbf{3 0}$ and $\mathbf{4 1}$ ) were too bulky to fit into the pocket, and were therefore also inactive. This is in agreement with the pyrrolamide pocket volume measurements and with our previous results [21, 23], where an indole moiety at this position was also unfavorable.

A combined quantum mechanics/ molecular mechanics quantum theory of atoms in molecules (QTAIM) study was performed to rationalize the observed SARs of these type I compounds. QTAIM calculations were performed as they enable evaluation of the molecular interactions that stabilize different ligand-enzyme complexes in detail [45-47]. We thus studied how the introduction of a methyl group and halogen atoms on the pyrrole ring influenced the strengths of interactions between the pyrrole $\mathrm{NH}$ and the side chain carboxylate group of Asp73 $\left(\mathrm{NH} \cdots \mathrm{O}_{\text {Asp73) }}\right.$. Table 2 shows the $\rho(\mathrm{r})$ values, which represent a measure of the hydrogen bond strength, of the $\mathrm{NH} \bullet \mathrm{O}_{\mathrm{Asp} 73}$ interactions for compounds 31-35, 37, and 38. The 4,5-dibromo substitution on the pyrrole ring in $\mathbf{3 1}$ resulted in significant increase in the strength of the $\mathrm{NH}$ •.- $\mathrm{O}_{\mathrm{Asp} 73}$ interaction compared to the unsubstituted pyrrole in 32 (Table 2). In contrast, introduction of an electron-donating methyl group at position 5 of the pyrrole moiety in $\mathbf{3 3}$ weakened the $\mathrm{NH} \bullet \mathrm{O}_{\mathrm{Asp} 73}$ hydrogen bond. This weakening effect of the 5-methyl group on the strength of the $\mathrm{NH} \cdot \cdots \mathrm{O}_{\mathrm{Asp} 73}$ interaction can be compensated for by the introduction of halogen atoms at positions 3 and 4 of the pyrrole moiety (compounds $\mathbf{3 4}, \mathbf{3 5}, \mathbf{3 7}, \mathbf{3 8}$; Table 2). As the pyrrole moiety is located inside the hydrophobic pocket of the E. coli DNA gyrase ATPbinding site, which is formed by residues Val43, Ala47, Val71, and Val120, the methyl group and halogen atoms can form a large number of hydrophobic contacts (Supporting Information, Figures S1, S2). Taken together, the cumulative effects of several hydrophobic interactions and the $\mathrm{NH} \cdots \mathrm{O}_{\mathrm{Asp} 73}$ hydrogen bond strength have important effects on the E. coli DNA gyrase inhibition. In general, the introduction of two halogen atoms at positions 3 and 4 of the pyrrole ring improved the $E$. coli DNA gyrase inhibition due to the increased numbers of hydrophobic 
interactions and the increased strength of the $\mathrm{NH} \cdots \mathrm{O}_{\mathrm{Asp} 73}$ hydrogen bond. The correlation obtained between the experimental $\mathrm{IC}_{50}$ values for $\mathbf{3 1 - 3 5 ,} \mathbf{3 7}$, and $\mathbf{3 8}$ and $\Sigma \rho_{(\mathrm{r})}$ is high, as shown in Supporting Information, Figure S3.

Table 2. Hydrogen bond strengths between the pyrrole NH and the Asp73 side-chain carboxylate group (NH ••• $\mathrm{O}_{\text {Asp73 }}$ ) obtained from the quantum theory of atoms in molecules calculations.

\begin{tabular}{cc}
\hline Compound & $\boldsymbol{\rho}_{(\mathbf{r})} \mathbf{N H} \bullet \bullet \mathbf{O}_{\text {Asp73 }}$ \\
\hline $\mathbf{3 1}$ & 0.0371 \\
$\mathbf{3 2}$ & 0.0353 \\
$\mathbf{3 3}$ & 0.0342 \\
$\mathbf{3 4}$ & 0.0352 \\
$\mathbf{3 5}$ & 0.0346 \\
$\mathbf{3 7}$ & 0.0354 \\
$\mathbf{3 8}$ & 0.0352 \\
\hline
\end{tabular}

$\rho_{(\mathrm{r})}$, atomic units (a.u.)

For all of these type I compounds, acids 31-41 were more potent $E$. coli DNA gyrase inhibitors than their corresponding methyl or ethyl ester counterparts $\mathbf{2 0 - 3 0}$, as they can form salt-bridge interactions with the guanidine group of the Arg136 side chain in addition to the hydrogen bond(s) formed in the case of the esters, which has also been observed previously [21, 23]. The inhibitory activities against $S$. aureus DNA gyrase were weaker, which confirmed the hypothesis of the more occlusive hydrophobic pocket in S. aureus compared to E. coli GyrB [21]. The most potent inhibitors of $S$. aureus DNA gyrase were 36 and 37, which contain the 3,4-dichloro-5-methyl-1H-pyrrole moiety with a smaller methyl substituent at position 5 compared to the 4,5-dibromopyrrole-containing compound 31, which is a weak S. aureus DNA gyrase inhibitor (Table 1). By substitution of the chlorine atom at position 3 of the pyrrole moiety of compound $\mathbf{3 7}$ with a bromine atom, the inhibition of $S$. aureus DNA gyrase remained similar (compound 39), while a bromine substituent at position 4 reduced the activity to a greater extent (compound 40). It can thus be concluded that $S$. aureus DNA gyrase tolerates 
methyl or chloro substituents at positions 4 and 5 of the pyrrole ring, while larger substituents lead to a loss of inhibitory activity. Inhibition of topoisomerase IV by these type I compounds was weak, although on the other hand, it was improved in some cases (e.g., compound 40, with IC50 values of $24 \mu \mathrm{M}$ and $0.73 \mu \mathrm{M}$ against $E$. coli and $S$. aureus topoisomerase IV, respectively) compared to the parent compound 31 (IC50 values of $74 \mu \mathrm{M}$ and $76 \mu \mathrm{M}$ against $E$. coli and $S$. aureus topoisomerase IV, respectively) (Table 1).

Table 3. Inhibition of Escherichia coli and Staphylococcus aureus DNA gyrase and topoisomerase IV by the 4,5,6,7-tetrahydrobenzo $[d]$ thiazole-2,6-diamine derivatives containing different moieties at 2-amino group (type II compounds).

\begin{tabular}{|c|c|c|c|c|c|c|}
\hline \multirow{3}{*}{ Compound } & \multirow{3}{*}{$\mathbf{R}^{1}$} & \multirow{3}{*}{$\mathbf{R}^{2}$} & \multirow{2}{*}{\multicolumn{2}{|c|}{$\begin{array}{c}\text { DNA gyrase } \\
\text { IC }_{50}[\mu \mathrm{M}] \text { or } \mathrm{RA}[\%]^{a}\end{array}$}} & \multirow{2}{*}{\multicolumn{2}{|c|}{$\begin{array}{c}\text { Topoisomerase IV } \\
\text { IC }_{50}[\mu \mathrm{M}] \text { or RA }[\%]^{a}\end{array}$}} \\
\hline & & & & & & \\
\hline & & & E. coli & S. aureus & E. coli & S. aureus \\
\hline $\mathrm{NB}^{b}$ & - & - & $\mathrm{IC}_{50}: 0.17$ & $\mathrm{IC}_{50}: 0.040$ & $\mathrm{IC}_{50}: 11$ & $\mathrm{IC}_{50}: 27$ \\
\hline 42 & & & $\mathrm{IC}_{50}: 0.084 \pm 0.025$ & RA: 73 & RA: 34 & RA: 95 \\
\hline 43 & & & $\mathrm{IC}_{50}: 0.047 \pm 0.011$ & $\begin{array}{c}\mathrm{IC}_{50}: 0.54 \pm \\
0.32\end{array}$ & RA: 82 & RA: 77 \\
\hline 44 & & & $\mathrm{IC}_{50}: 0.17 \pm 0.13$ & RA: 33 & RA: 100 & RA: 93 \\
\hline 50 & & & $\mathrm{IC}_{50}: 6.8 \pm 0.3$ & n.t. ${ }^{c}$ & n.t. & n.t. \\
\hline 51 & & s- & $\mathrm{IC}_{50}: 1.9 \pm 0.2$ & RA: 75 & RA: 100 & RA: 100 \\
\hline 52 & & & $\mathrm{IC}_{50}: 1.4 \pm 0.2$ & n.t. & n.t. & n.t. \\
\hline 53 & & & $\mathrm{IC}_{50}: 0.23 \pm 0.08$ & RA: 74 & RA: 100 & RA: 99 \\
\hline
\end{tabular}




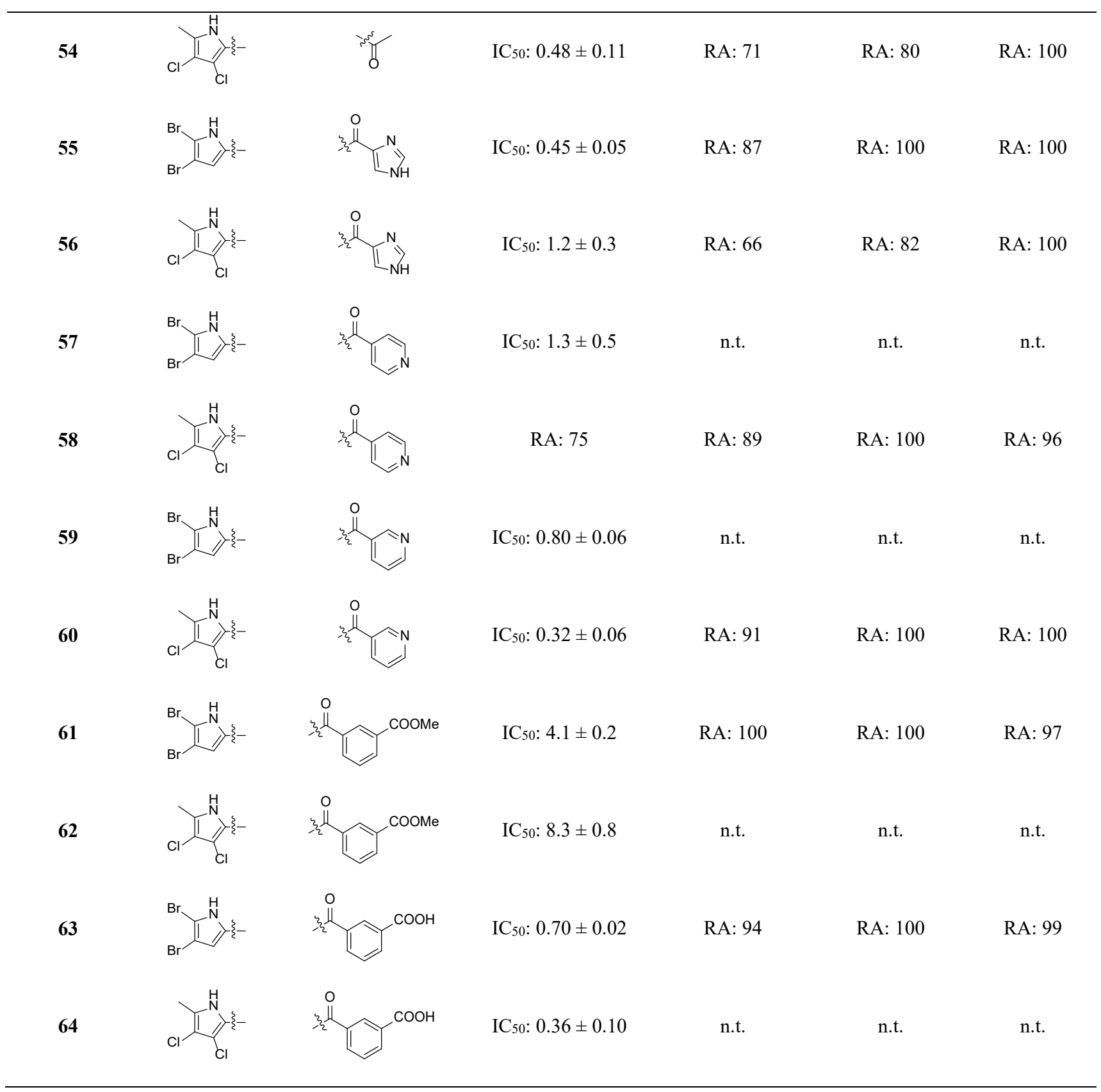

${ }^{a} R A$, Residual activity of the enzyme at $10 \mu \mathrm{M}$ concentration of the tested compound.

${ }^{b} \mathrm{NB}$, novobiocin was used as positive control.

$c_{\text {n.t., not tested. }}$

For the type II compounds (Table 3), the effects of the replacement of the malonyl group by different aliphatic and aromatic moieties that can form hydrogen bonds with Arg76 and/or Arg136 were investigated. In general, compounds based on 4,5-dibromopyrrole $(\mathbf{4 2}, \mathbf{5 0 , 5 2 , 5 5}$, $57,59,61,63)$ and 3,4-dichloro-5-methylpyrrole $(43,44,51,53,54,56,58,60,62,64)$ had similar inhibitory potencies against $E$. coli DNA gyrase, but were typically weaker inhibitors 
of this enzyme than most of the malonyl-based compounds in Table 1. The most potent type II compounds were hydrazides 42 and $\mathbf{4 3}$, with $E$. coli DNA gyrase $\mathrm{IC}_{50}$ values of $0.084 \mu \mathrm{M}$ and $0.047 \mu \mathrm{M}$, respectively. These two compounds showed improved inhibition in comparison to their ester counterparts $\mathbf{2 0}$ and 26, but were weaker inhibitors than their corresponding carboxylic acids $\mathbf{3 1}$ and 37. The hydrazide group is not ionizable under physiological conditions, and cannot form ionic interactions with the Arg136 side chain, in contrast to carboxylic acids. On the other hand, hydrazide is an H-bond donor/ acceptor group and can still interact with the Arg136 guanidine group, which explains the observed inhibition potency. The introduction of aromatic rings, such as different imidazole, pyridine, and substituted phenyl rings (compounds 55-64), resulted in weaker inhibition of all four of these enzymes compared to the malonate derivatives of the type I series. All of the type II compounds were generally weak E. coli topoisomerase IV and $S$. aureus DNA gyrase and topoisomerase IV inhibitors (Table 3), which suggests that the moiety attached to the 2-amino group on the 4,5,6,7tetrahydrobenzo $[d]$ thiazole also has a very important role in the binding of compounds to the enzyme ATP-binding site. The exception is the hydrazide 43 , which was among the most potent S. aureus DNA gyrase inhibitors of the series, with an $\mathrm{IC}_{50}$ of $0.54 \mu \mathrm{M}$ (Table 3).

Table 4. Inhibition of Escherichia coli and Staphylococcus aureus DNA gyrase and topoisomerase IV by the 4,5,6,7-tetrahydrobenzo $[d]$ thiazole-2,6-diamine derivatives containing the 2-(2-aminothiazol-4-yl)acetyl moiety at 2-amino group (type III compounds).

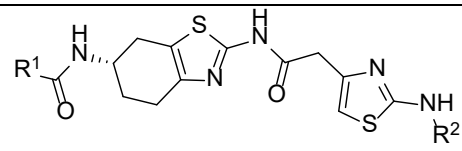

\begin{tabular}{|c|c|c|c|c|c|c|}
\hline \multirow{3}{*}{ Compound } & \multirow{3}{*}{$\mathbf{R}^{1}$} & \multirow{3}{*}{$\mathbf{R}^{2}$} & & & \multirow{2}{*}{\multicolumn{2}{|c|}{$\begin{array}{c}\text { Topoisomerase IV } \\
\text { IC }_{50}[\mu \mathrm{M}] \text { or RA }[\%]^{a}\end{array}$}} \\
\hline & & & \multicolumn{2}{|c|}{$\mathrm{IC}_{50}[\mu \mathrm{M}]$ or RA $[\%]^{a}$} & & \\
\hline & & & E. coli & S. aureus & E. coli & S. aureus \\
\hline $\mathrm{NB}^{b}$ & - & - & $\mathrm{IC}_{50}: 0.17$ & $\mathrm{IC}_{50}: 0.040$ & IC50: 11 & $\mathrm{IC}_{50}: 27$ \\
\hline
\end{tabular}


65

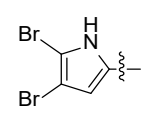

66<smiles>Cc1[nH]c(Cl)c(Cl)c1Cl</smiles>

67<smiles>Brc1cc[nH]c1Br</smiles>

68

69

70

71<smiles>Cc1[nH]c(Cl)c(Cl)c1Cl</smiles><smiles>Brc1c[Y][nH]c1Br</smiles><smiles>Cc1[nH]cc(Cl)c1Cl</smiles><smiles>CC(C)C(C)(C)C</smiles><smiles>CC(C)=O</smiles><smiles>[Y]C(=O)NCC</smiles>

$\mathrm{IC}_{50}: 0.15 \pm 0.03$<smiles>CCNC(C)=O</smiles>

$\mathrm{IC}_{50}: 0.11 \pm 0.01$

RA: 67<smiles>CC(=O)OC(C)(C)C</smiles>

$\mathrm{IC}_{50}: 0.34 \pm 0.10$

RA: 100

RA: 98

RA: 99<smiles>CC(=O)OC(C)(C)C</smiles>

$\mathrm{IC}_{50}: 0.14 \pm 0.03$

RA: 76

RA: 100

RA: 99

$-\mathrm{H}$

RA: 70

RA: 100

RA: 100

${ }^{a} \mathrm{RA}$, residual activity of the enzyme at $10 \mu \mathrm{M}$ concentration of the tested compound.

${ }^{b} \mathrm{NB}$, novobiocin was used as positive control.

${ }^{c}$ n.t., not tested.

The possibility of formation of cation- $\pi$ interactions with the Arg136 side chain was further explored with the aminothiazole derivatives (type III compounds). These analogs had generally improved potencies in the E. coli DNA gyrase assay compared to 54, which was without the aminothiazole moiety (Tables 3,4). However, the SAR data suggest that a carbonyl bound to 2-amino group of the aminothiazole moiety (compounds 65-70), is important for $E$. coli DNA gyrase inhibition ( $\mathrm{IC}_{50}$ between $0.11 \mu \mathrm{M}$ and $0.34 \mu \mathrm{M}$ ), as compound 71 with a free 2-amino group was a weak inhibitor, with an $\mathrm{IC}_{50}$ of $2.0 \mu \mathrm{M}$ (Table 4). All of the type III compounds were generally devoid of $S$. aureus DNA gyrase and topoisomerase IV and E. coli topoisomerase IV inhibitory activities (Table 4).

Selected compounds of types I-III were also tested for their inhibitory activities against human topoisomerase II $\alpha$, to evaluate their selectivity over the structurally and functionally similar human ATP-binding enzyme. Compounds 26, 29, 32, 34, 37, 40, and 41 of the type I 
series and compound $\mathbf{6 0}$ of the type II series were inactive at $100 \mu \mathrm{M}$, which showed their selectivity for bacterial over human topoisomerases. Type III compounds 68 and 71 inhibited human topoisomerase II $\alpha$ with residual activities of $16 \%$ and $68 \%$ at $100 \mu \mathrm{M}$, but were completely inactive at $10 \mu \mathrm{M}$.

\subsection{Antibacterial activities}

All of the DNA gyrase and topoisomerase IV inhibitors were tested against two Gram-positive (Enterococcus faecalis ATCC 29212, S. aureus ATCC 25923) and two Gram-negative (E. coli ATCC 25922, Pseudomonas aeruginosa ATCC 27853) bacterial strains. Additionally, these compounds were tested against two E. coli mutant strains, as the lpxC deletion mutant with an impaired outer membrane (E. coli JD17464), and the tolC deletion mutant with a defective efflux pump (E. coli JW5503). Preliminary tests were carried out at $50 \mu \mathrm{M}$, and inhibition of growth was measured after $24 \mathrm{~h}$ of incubation. The MICs was determined only for the compounds with $>90 \%$ growth inhibition at $50 \mu \mathrm{M}$. The results of preliminary screening are given in Supporting Information, Table S1, and the MICs for the active compounds are given in Table 5.

Table 5. Minimum inhibitory concentrations of the DNA gyrase and topoisomerase IV inhibitors.

\begin{tabular}{|c|c|c|c|c|c|c|}
\hline \multirow[t]{3}{*}{ Compound } & \multicolumn{6}{|c|}{$\mathrm{MIC}[\boldsymbol{\mu M}]^{a}$} \\
\hline & \multirow{2}{*}{$\begin{array}{c}\text { E. faecalis } \\
\text { ATCC } 29212\end{array}$} & \multirow{2}{*}{$\begin{array}{c}\text { S. aureus } \\
\text { ATCC } 25923\end{array}$} & \multicolumn{3}{|c|}{ E. coli } & \multirow{2}{*}{$\begin{array}{l}\text { P. aeruginosa } \\
\text { ATCC } 27853\end{array}$} \\
\hline & & & ATCC 25922 & JW5503 & JD17464 & \\
\hline 24 & $>50$ & $>50$ & $>50$ & $50(23)$ & $>50$ & $>50$ \\
\hline 26 & $50(22)$ & $50(22)$ & $>50$ & $12.5(6)$ & $>50$ & $>50$ \\
\hline 27 & $25(13)$ & $25(13)$ & $>50$ & $12.5(7)$ & $>50$ & $>50$ \\
\hline 28 & $>50$ & $>50$ & $>50$ & $12.5(6)$ & $>50$ & $>50$ \\
\hline 29 & $12.5(6)$ & $>50$ & $>50$ & $12.5(6)$ & $>50$ & $>50$ \\
\hline 42 & $>50$ & $>50^{\mathrm{b}}$ & $>50$ & $25(13)$ & $>50$ & $>50$ \\
\hline
\end{tabular}




\begin{tabular}{|c|c|c|c|c|c|c|}
\hline 43 & $>50$ & $>50$ & $>50$ & $25(11)$ & $>50$ & $>50$ \\
\hline 44 & $50(24)$ & $50(24)$ & $>50$ & $25(12)$ & $>50$ & $>50$ \\
\hline 52 & $>50$ & $>50$ & $>50$ & $12.5(6)$ & $>50$ & $>50$ \\
\hline 55 & $>50$ & $>50$ & $>50$ & $6.25(3)$ & $>50$ & $>50$ \\
\hline 59 & $>50$ & $>50$ & $>50$ & $12.5(7)$ & $>50$ & $>50$ \\
\hline 65 & $>50$ & $>50$ & $>50$ & $6.25(4)$ & $>50$ & $>50$ \\
\hline 67 & $>50$ & $>50$ & $>50$ & $3.13(2)$ & $>50$ & $>50$ \\
\hline 68 & $50(28)$ & $>50^{\mathrm{b}}$ & $>50$ & $>50$ & $>50$ & $>50$ \\
\hline Ciprofloxacin & 3.0 & 1.5 & 0.05 & 0.015 & 0.12 & 3.0 \\
\hline
\end{tabular}

${ }^{a}$ Minimum inhibitory concentration that inhibits the growth of bacteria by $\geq 90 \%$. Values in parentheses are MIC values expressed in $\mu \mathrm{g} / \mathrm{mL}$.

${ }^{b}$ tested against $S$. aureus ATCC 29213.

Despite potent inhibition of E. coli DNA gyrase by several of these compounds, and especially those from the type I series, they were all devoid of antibacterial activities against the tested Gram-negative wild-type E. coli and P. aeruginosa (Supporting Information, Table $\mathrm{S} 1$, Table 5). These results can be attributed to cell-wall penetration issues of these compounds, or to their efflux, as some of them showed improved antibacterial activities against E. coli JW5503, which has the defective TolC efflux pump. Compound $\mathbf{6 7}$ was the most potent against E. coli JW5503, with a MIC of $3.13 \mu \mathrm{M}$. From the type I series, the esters were more potent than their acid counterparts, while for the types II and III series, the 4,5-dibromopyrrole-based compounds appeared to have better activities against E. coli JW5503 than their 3,4-dichloro-5methylpyrrole-based analogs (e.g., 59 vs. 60; 67 vs. 68; see Table 5). Most of the antibacterially active compounds are potent $E$. coli DNA gyrase inhibitors that are lipophilic and do not contain ionizable groups.

In general, the antibacterial activities of these tested compounds were better against Gram-positive $S$. aureus and E. faecalis than against Gram-negative E. coli and P. aeruginosa (Supporting Information, Table S1, Table 5). The most potent compound against S. aureus was 
27, with a MIC of $25 \mu \mathrm{M}$, while for E. faecalis, 29 had the lowest MIC of the series, at 12.5 $\mu \mathrm{M}$ (Table 5). Both of these compounds are methyl esters, which were weaker inhibitors of DNA gyrase than their carboxylic acid counterparts $\mathbf{3 8}$ and 40, respectively. This might be explained by the excessive polarity and acidity of the carboxylic acids (Table 1); they therefore cannot permeate through the bacterial cell wall, which results in low on-target concentrations of these inhibitors. In addition, compounds 24, 27 and 29 showed promising activities also against methicillin-resistant $S$. aureus, vancomycin-intermediate $S$. aureus, and Enterococcus faecium, with MICs between $4 \mu \mathrm{g} / \mathrm{mL}$ and $16 \mu \mathrm{g} / \mathrm{mL}$ (Table 6). Moreover, compounds 27 and 29 displayed no cross-resistance with fluoroquinolones as they showed improved MIC values against fluoroquinolone-resistant strains of E. coli compared to the wild-type (Table 7). In conclusion here, the correlation between DNA gyrase/ topoisomerase IV inhibition and antibacterial activity against Gram-positive and Gram-negative strains was weak, as has been reported previously $[10,48]$.

Table 6. Antibacterial activities of 24, 27, and 29 against additional Gram-positive bacterial strains.

\begin{tabular}{|c|c|c|c|c|}
\hline \multirow[t]{3}{*}{ Compound } & \multicolumn{4}{|c|}{$\mathrm{MIC}[\mu \mathrm{g} / \mathrm{mL}]$} \\
\hline & \multicolumn{3}{|c|}{ S. aureus } & \multirow{2}{*}{$\begin{array}{c}\text { E. faecium } \\
\text { ATCC } 700221\end{array}$} \\
\hline & ATCC 29213 & ATCC 43300 (MRSA) & ATCC 700699 (VISA) & \\
\hline 24 & 64 & 64 & 32 & 64 \\
\hline 27 & 8 & 16 & 8 & 16 \\
\hline 29 & 8 & 8 & 4 & 8 \\
\hline
\end{tabular}

MRSA, methicillin-resistant S. aureus

VISA, vancomycin-intermediate Staphylococcus aureus 
Table 7. Antibacterial activities of $\mathbf{2 7}$ and $\mathbf{2 9}$ against fluoroquinolone-resistant $E$. coli.

\begin{tabular}{|c|c|c|c|c|c|}
\hline \multirow[t]{4}{*}{ Compound } & \multicolumn{5}{|c|}{$\mathrm{MIC}[\mu \mathrm{g} / \mathrm{mL}]^{a}$} \\
\hline & \multicolumn{5}{|c|}{ E. coli K-12 MG1655 } \\
\hline & wild & GyrA & GyrA S83L, & GyrA S83L, & GyrA S83L, D87N; \\
\hline & type & S83L & D87N & D87Y; ParC S80I & ParC S80I, E84G \\
\hline ciprofloxacin & 0.5 & 0.156 & 0.313 & 12.5 & 50 \\
\hline 27 & $>50$ & 25 & 6.25 & 25 & 25 \\
\hline 29 & $>50$ & 25 & 12.5 & 25 & 25 \\
\hline
\end{tabular}

\section{CONCLUSIONS}

Three series of structural analogs of 4,5,6,7-tetrahydrobenzo[d]thiazole-based DNA gyrase B inhibitors were designed, synthesized and biologically evaluated. The results of the in vitro E. coli and S. aureus DNA gyrase and topoisomerase IV inhibition assays showed improved activities of some of the type I compounds against all four enzymes, when compared to our previously reported series [21]. The type II and III compounds showed nanomolar E. coli DNA gyrase inhibition, but were generally weak S. aureus DNA gyrase and E. coli and S. aureus topoisomerase IV inhibitors. Importantly, the improved enzyme inhibition of the type I compounds also resulted in antibacterial activities against some Gram-positive strains, which was not seen for in the previously reported series of 4,5,6,7-tetrahydrobenzo[ $d]$ thiazoles [21]. Compound 29 inhibited $E$. coli and $S$. aureus DNA gyrase with $\mathrm{IC}_{50}$ values of $0.056 \mu \mathrm{M}$ and 3.7 $\mu \mathrm{M}$, respectively, and showed activity against $S$. aureus, methicillin-resistant S. aureus, vancomycin-intermediate $S$. aureus, and E. faecium, with MICs between $4 \mu \mathrm{g} / \mathrm{mL}$ and 16 $\mu \mathrm{g} / \mathrm{mL}$. Compound 29 thus represents a good starting point for further optimization.

\section{FUTURE PERSPECTIVE}


The emerging field of multidrug resistance among bacteria calls for urgent need to develop novel effective antibiotics with alternative mechanisms of action, which would more likely not be as susceptible to the pre-existing resistance mechanisms. A lot of efforts have been made in the last decades to identify novel ATPase inhibitors of DNA gyrase and topoisomerase IV. Especially in the last few years, some of them have reached clinical trials [11], which again awakened optimism in these new-class antibacterials after novobiocin was withdrawn from the market in 2011. However, none of these compounds has so far been approved for therapeutic use. For sure, economical reasons hinder the development of novel antibacterials, because newly discovered antibiotics are usually held in reserve and prescribed only after the available treatment options have been exhausted. Meanwhile, in the case of first-in-class antibacterial agents the situation is better and the initial investment often pays off, such as in the case of linezolid and daptomycin [10]. One of the possible strategies for improving antibacterial activities of the presented 4,5,6,7-tetrahydrobenzo[ $[d]$ thiazole class of GyrB inhibitors would be to make compounds less acidic in order to improve penetration through the bacterial cell wall. In addition, enzyme inhibition should be improved further by strengthening the salt bridge formation with $\operatorname{Arg} 136$ and/or cation- $\pi$ interaction with $\operatorname{Arg} 76$ (E. coli numbering). The substantial amount of accumulated knowledge in the field of DNA gyrase and topoisomerase IV inhibitors offers opportunity to approach the development of these inhibitors with greater confidence in the future. Thus, clinically approved drugs from this class are hopefully not far away.

\section{SUMMARY POINTS}

- DNA gyrase and topoisomerase IV are important targets for designing novel antibacterials to overcome bacterial resistance problems. 
- Starting from our previous series of the 4,5,6,7-tetrahydrobenzo[d]thiazole-based DNA gyrase B inhibitors, a structure-activity relationship of these compounds was further explored and up-graded.

- Newly prepared analogs showed nanomolar enzyme inhibition of DNA gyrase and topoisomerase IV and the most potent was 40, with an $\mathrm{IC}_{50}$ of $0.016 \mu \mathrm{M}$ against Escherichia coli DNA gyrase.

- Compounds also showed improved in vitro antibacterial activity against Gram-positive strains and analog 29 possessed activity against MRSA and VISA with MICs between $4 \mu \mathrm{g} / \mathrm{mL}$ and $8 \mu \mathrm{g} / \mathrm{mL}$, thus representing a promising hit for further optimization studies.

\section{FIGURE LEGENDS}

Figure 1. DNA gyrase inhibitor novobiocin, and two novel DNA gyrase and topoisomerase IV inhibitors in clinical development.

Figure 2. Representative GyrB and ParE inhibitors of natural and synthetic origins.

Figure 3. Interactions of representative compound $\mathbf{I}$ of the first generation of 4,5,6,7tetrahydrobenzo $[d]$ thiazole-based inhibitors in the E. coli GyrB ATP-binding site, as predicted by molecular docking. Hydrophobic interactions are shown in yellow, hydrogen bonds as dashed arrows and negative charge is shown in red.

\section{TABLE LEGENDS}

Table 1. Inhibition of Escherichia coli and Staphylococcus aureus DNA gyrase and topoisomerase IV by the 4,5,6,7-tetrahydrobenzo[ $d]$ thiazoles $\mathbf{2 0 - 4 1}$, which contain differently substituted pyrrole moieties (type I compounds). 
Table 2. Hydrogen bond strengths between the pyrrole NH and the Asp73 side-chain carboxylate group $\left(\mathrm{NH} \cdots \mathrm{O}_{\mathrm{Asp} 73}\right)$ obtained from the quantum theory of atoms in molecules calculations.

Table 3. Inhibition of Escherichia coli and Staphylococcus aureus DNA gyrase and topoisomerase IV by the 4,5,6,7-tetrahydrobenzo[ $[d]$ thiazole-2,6-diamine derivatives containing different moieties at 2-amino group (type II compounds).

Table 4. Inhibition of Escherichia coli and Staphylococcus aureus DNA gyrase and topoisomerase IV by the 4,5,6,7-tetrahydrobenzo[ $[d]$ thiazole-2,6-diamine derivatives containing the 2-(2-aminothiazol-4-yl)acetyl moiety at 2-amino group (type III compounds).

Table 5. Minimum inhibitory concentrations of the DNA gyrase and topoisomerase IV inhibitors.

Table 6. Antibacterial activities of 24, 27, and 29 against additional Gram-positive bacterial strains.

Table 7. Antibacterial activities of 27 and 29 against fluoroquinolone-resistant E. coli.

\section{ASSOCIATED CONTENT}

\section{Supplementary Information}

The full data for the synthetic procedures and antibacterial activities of the compounds, inhibitory curves of in vitro enzyme inhibition for selected compounds for all enzymes, the NMR spectra of the representative compounds, and the molecular modeling Figures are given in the Supplementary Information. This material is available via the internet.

\section{Author contributions}


The manuscript was written with contributions from all of the authors. All of the authors have given approval to the final version of the manuscript.

\section{Conflicts of interest}

The authors declare that they have no conflicts of interest, including no financial, personal, or other relationships with other people or organizations.

\section{ABBREVIATIONS}

American type culture collection (ATCC); 1,1'-carbonyldiimidazole (CDI); dimethylsulfoxide (DMSO); 1-ethyl-3-(3-(dimethylamino)propyl)-carbodiimide (EDC); DNA gyrase A (GyrA); DNA gyrase B (GyrB); 1-hydroxybenzotriazole (HOBt); minimum inhibitory concentration (MIC); topoisomerase IV subunit A (ParC); topoisomerase IV subunit B (ParE); quantum theory of atoms in molecules (QTAIM); structure-activity relationships (SARs); $N, N, N^{\prime}, N^{\prime}-$ tetramethyl-O-(benzotriazol-1-yl)uroniumtetrafluoroborate (TBTU).

\section{REFERENCES}

1. Santajit S, Indrawattana N. Mechanisms of antimicrobial resistance in ESKAPE pathogens. Biomed. Res. Int. 2016, 2475067 (2016).

2. World Health Organization. WHO publishes list of bacteria for which new antibiotics are urgently needed (2017). http://www.who.int/news-room/detail/27-02-2017-whopublishes-list-of-bacteria-for-which-new-antibiotics-are-urgently-needed.

3. Fernandes P, Martens E. Antibiotics in late clinical development. Biochem. Pharmacol. 133, 152-163 (2017).

4. Gonzalez-Bello C. Antibiotic adjuvants - a strategy to unlock bacterial resistance to antibiotics. Bioorg. Med. Chem. Lett. 27(18), 4221-4228 (2017).

5. Tse-Dinh YC. Targeting bacterial topoisomerases: how to counter mechanisms of resistance. Future Med. Chem. 8(10), 1085-1100 (2016).

6. Sissi C, Palumbo M. In front of and behind the replication fork: bacterial type IIA topoisomerases. Cell. Mol. Life Sci. 67(12), 2001-2024 (2010).

7. Collin F, Karkare S, Maxwell A. Exploiting bacterial DNA gyrase as a drug target: current state and perspectives. Appl. Microbiol. Biotechnol. 92(3), 479-497 (2011).

8. Chopra S, Matsuyama K, Tran T et al. Evaluation of gyrase B as a drug target in Mycobacterium tuberculosis. J. Antimicrob. Chemother. 67(2), 415-421 (2012).

9. Tomašič T, Peterlin Mašič L. Prospects for developing new antibacterials targeting bacterial type IIA topoisomerases. Curr. Top. Med. Chem. 14(1), 130-151 (2014).

10. Bisacchi GS, Manchester JI. A new-class antibacterial - almost. Lessons in drug discovery and development: a critical analysis of more than 50 years of effort toward 
ATPase inhibitors of DNA gyrase and topoisomerase IV. ACS Infect. Dis. 1(1), 4-41 (2015).

** An exhaustive and detailed overview of development of DNA gyrase and topoisomerase IV inhibitors as well as critical analysis of research efforts in this field since 1960s.

11. Durcik M, Tomašič T, Zidar N et al. ATP-competitive DNA gyrase and topoisomerase IV inhibitors as antibacterial agents. Expert Opin. Ther. Pat. 29(3), 171-180 (2019).

* Recent review on development of ATP-competitive DNA gyrase and topoisomerase IV inhibitors in the last 10 years.

12. Anderson VE, Osheroff N. Type II topoisomerases as targets for quinolone antibacterials: turning Dr. Jekyll into Mr. Hyde. Curr. Pharm. Des. 7(5), 337-353 (2001).

13. Drlica K, Malik M, Kerns RJ, Zhao X. Quinolone-mediated bacterial death. Antimicrob. Agents Chemother. 52(2), 385-392 (2008).

14. Sanyal G, Doig P. Bacterial DNA replication enzymes as targets for antibacterial drug discovery. Expert Opin. Drug Discov. 7(4), 327-339 (2012).

15. Taylor SN, Morris DH, Avery AK et al. Gepotidacin for the treatment of uncomplicated urogenital gonorrhea: a phase 2, randomized, dose-ranging, single-oral dose evaluation. Clin. Infect. Dis. 67(4), 504-512 (2018).

16. De Ambrogi M, McConnell J, Mushtaq A. Highlights from the 26th ECCMID. Lancet Infect. Dis. 16(6), 645-647 (2016).

17. Hameed PS, Solapure S, Mukherjee K et al. Optimization of pyrrolamides as mycobacterial GyrB ATPase inhibitors: structure-activity relationship and in vivo efficacy in a mouse model of tuberculosis. Antimicrob. Agents Chemother. 58(8), 49934994 (2014).

18. Škedelj V, Tomašič T, Mašič LP, Zega A. ATP-binding site of bacterial enzymes as a target for antibacterial drug design. J. Med. Chem. 54(4), 915-929 (2011).

19. Tari LW, Li X, Trzoss M et al. Tricyclic GyrB/ParE (TriBE) inhibitors: a new class of broad-spectrum dual-targeting antibacterial agents. PLoS One 8(12), e84409 (2013).

20. Aldred KJ, Kerns RJ, Osheroff N. Mechanism of quinolone action and resistance. Biochemistry 53(10), 1565-1574 (2014).

21. Tomašič T, Katsamakas S, Hodnik Ž et al. Discovery of 4,5,6,7-tetrahydrobenzo[1,2d] thiazoles as novel DNA gyrase inhibitors targeting the ATP-binding site. J. Med. Chem. 58(14), 5501-5521 (2015).

* The article describing the first generation of 4,5,6,7-tetrahydrobenzo[d]thiazolebased DNA gyrase inhibitors and initial structure-activity relationship studies.

22. Zidar N, Tomašič T, Macut $\mathrm{H}$ et al. New $N$-phenyl-4,5-dibromopyrrolamides and $N$ phenylindolamides as ATPase inhibitors of DNA gyrase. Eur. J. Med. Chem. 117, 197211 (2016).

23. Zidar $\mathrm{N}$, Macut $\mathrm{H}$, Tomašič $\mathrm{T}$ et al. $\mathrm{N}$-Phenyl-4,5-dibromopyrrolamides and $\mathrm{N}$ phenylindolamides as ATP competitive DNA gyrase B inhibitors: design, synthesis, and evaluation. J. Med. Chem. 58(15), 6179-6194 (2015).

24. Durcik M, Lovison D, Skok Ž et al. New $N$-phenylpyrrolamide DNA gyrase B inhibitors: optimization of efficacy and antibacterial activity. Eur. J. Med. Chem. 154, 117-132 (2018). 
25. Durcik M, Tammela $\mathrm{P}$, Barančoková $\mathrm{M}$ et al. Synthesis and evaluation of $N$ phenylpyrrolamides as DNA gyrase B inhibitors. ChemMedChem 13(2), 186-198 (2018).

26. Gjorgjieva M, Tomašič T, Barančoková $\mathrm{M}$ et al. Discovery of benzothiazole scaffoldbased DNA gyrase B inhibitors. J. Med. Chem. 59(19), 8941-8954 (2016).

* Additional structure-activity relationship studies on benzothiazole-2,6-diamine scaffold with X-ray structure of DNA gyrase B in complex with inhibitor.

27. Tomašič T, Mirt M, Barančoková M et al. Design, synthesis and biological evaluation of 4,5-dibromo- $N$-(thiazol-2-yl)-1H-pyrrole-2-carboxamide derivatives as novel DNA gyrase inhibitors. Bioorg. Med. Chem. 25(1), 338-349 (2017).

* A series of $»$ reversed $«$ and ring-opened DNA gyrase inhibitors based on the 4,5,6,7tetrahydrobenzo $[d]$ thiazole scaffold.

28. Flatman RH, Eustaquio A, Li SM, Heide L, Maxwell A. Structure-activity relationships of aminocoumarin-type gyrase and topoisomerase IV inhibitors obtained by combinatorial biosynthesis. Antimicrob. Agents Chemother. 50(4), 1136-1142 (2006).

29. Phillips JW, Goetz MA, Smith SK et al. Discovery of Kibdelomycin, A potent new class of bacterial type II topoisomerase inhibitor by chemical-genetic profiling in Staphylococcus aureus. Chem. Biol. 18(8), 955-965 (2011).

30. Basarab GS, Hill PJ, Garner CE et al. Optimization of pyrrolamide topoisomerase II inhibitors toward identification of an antibacterial clinical candidate (AZD5099). $J$. Med. Chem. 57(14), 6060-6082 (2014).

31. Yule IA, Czaplewski LG, Pommier S, Davies DT, Narramore SK, Fishwick CWG. Pyridine-3-carboxamide-6-yl-ureas as novel inhibitors of bacterial DNA gyrase: structure based design, synthesis, SAR and antimicrobial activity. Eur. J. Med. Chem. 86, 31-38 (2014).

32. Baba T, Ara T, Hasegawa $\mathrm{M}$ et al. Construction of Escherichia coli K-12 in-frame, single-gene knockout mutants: the Keio collection. Mol. Syst. Biol. 2, 2006.0008 (2006).

33. Nyerges Á, Csörgő B, Nagy I et al. A highly precise and portable genome engineering method allows comparison of mutational effects across bacterial species. Proc. Natl. Acad. Sci. U. S. A. 113, 2502-2507 (2016).

34. Nyerges Á, Csörgő B, Draskovits G et al. Directed evolution of multiple genomic loci allows the prediction of antibiotic resistance. Proc. Natl. Acad. Sci. U. S. A. 115, E5726E5735 (2018).

35. Brino L, Urzhumtsev A, Mousli M et al. Dimerization of Escherichia coli DNA-gyrase B provides a structural mechanism for activating the ATPase catalytic center. J. Biol. Chem. 275(13), 9468-9475 (2000).

36. Morris GM, Huey R, Lindstrom W et al. AutoDock4 and AutoDockTools4: automated docking with selective receptor flexibility. J. Comput. Chem. 30(16), 2785-2791 (2009).

37. Guo XC, He DY, Huang L, Liu LM, Liu LJ, Yang HJ. Strain energy in enzyme-substrate binding: an energetic insight into the flexibility versus rigidity of enzyme active site. Comput. Theor. Chem. 995, 17-23 (2012).

38. Guo XC, He DY, Liu LM, Kuang RY, Liu LJ. Use of QM/MM scheme to reproduce macromolecule-small molecule noncovalent binding energy. Comput. Theor. Chem. 991, 134-140 (2012).

39. Wang JM, Wolf RM, Caldwell JW, Kollman PA, Case DA. Development and testing of a general amber force field. J. Comput. Chem. 25(9), 1157-1174 (2004).

40. Gaussian 09, Revision A.02, M. J. Frisch, G. W. Trucks, H. B. Schlegel, G. E. Scuseria, M. A. Robb, J. R. Cheeseman, G. Scalmani, V. Barone, G. A. Petersson, H. Nakatsuji, 
X. Li, M. Caricato, A. Marenich, J. Bloino, B. G. Janesko, R. Gomperts, B. Mennucci, H. P. Hratchian, J. V. Ortiz, A. F. Izmaylov, J. L. Sonnenberg, D. Williams-Young, F. Ding, F. Lipparini, F. Egidi, J. Goings, B. Peng, A. Petrone, T. Henderson, D. Ranasinghe, V. G. Zakrzewski, J. Gao, N. Rega, G. Zheng, W. Liang, M. Hada, M. Ehara, K. Toyota, R. Fukuda, J. Hasegawa, M. Ishida, T. Nakajima, Y. Honda, O. Kitao, H. Nakai, T. Vreven, K. Throssell, J. A. Montgomery, Jr., J. E. Peralta, F. Ogliaro, M. Bearpark, J. J. Heyd, E. Brothers, K. N. Kudin, V. N. Staroverov, T. Keith, R. Kobayashi, J. Normand, K. Raghavachari, A. Rendell, J. C. Burant, S. S. Iyengar, J. Tomasi, M. Cossi, J. M. Millam, M. Klene, C. Adamo, R. Cammi, J. W. Ochterski, R. L. Martin, K. Morokuma, O. Farkas, J. B. Foresman, and D. J. Fox, Gaussian, Inc., Wallingford CT, 2016.

41. Bader RFW. Atoms in molecules. Acc. Chem. Res. 18(1), 9-15 (1985).

42. Lu T, Chen FW. Multiwfn: a multifunctional wavefunction analyzer. J. Comput. Chem. 33(5), 580-592 (2012).

43. Schneider CS, Mierau J. Dopamine autoreceptor agonists - resolution and pharmacological activity of 2,6-diaminotetrahydrobenzothiazole and an aminothiazole analog of apomorphine. J. Med. Chem. 30(3), 494-498 (1987).

44. Breeze AL, Green OM, Hull KG et al. Pyrrol derivatives with antibacterial activity. WO 2005/026149 A1 (2005).

45. Vettorazzi M, Menendez C, Gutierrez L, Andujar S, Appignanesi G, Enriz RD. Theoretical models to predict the inhibitory effect of ligands of sphingosine kinase 1 using QTAIM calculations and hydrogen bond dynamic propensity analysis. J. Comput. Aided Mol. Des. 32(7), 781-791 (2018).

46. Tosso RD, Andujar SA, Gutierrez L et al. Molecular modeling study of dihydrofolate reductase inhibitors. Molecular dynamics simulations, quantum mechanical calculations, and experimental corroboration. J. Chem. Inf. Model. 53(8), 2018-2032 (2013).

47. Andujar SA, Tosso RD, Suvire FD et al. Searching the "biologically relevant" conformation of dopamine: a computational approach. J. Chem. Inf. Model. 52(1), 99112 (2012).

46. Manchester JI, Dussault DD, Rose JA et al. Discovery of a novel azaindole class of antibacterial agents targeting the ATPase domains of DNA gyrase and topoisomerase IV. Bioorg. Med. Chem. Lett. 22(15), 5150-5156 (2012). 